\title{
Transformative education: towards a relational, justice-oriented approach to sustainability
}

\author{
Zack Walsh
}

One Project, San Francisco, California, USA

Jessica Böhme

Leuphana University of Lüneburg, Luneburg, Germany

Brooke D. Lavelle

Courage of Care Coalition, Oakland, California, USA, and

Christine Wamsler

Centre for Sustainability Studies, Lund University, Lund, Sweden

\begin{abstract}
Purpose - This paper aims to increase related knowledge across personal, social and ecological dimensions of sustainability and how it can be applied to support transformative learning.

Design/methodology/approach - The paper provides a reflexive case study of the design, content and impact of a course on eco-justice that integrates relational learning with an equity and justice lens. The reflexive case study provides a critical, exploratory self-assessment, including interviews, group discussions and surveys with key stakeholders and course participants.

Findings - The results show how relational approaches can support transformative learning for sustainability and provide concrete practices, pathways and recommendations for curricula development that other universities/training institutions could follow or learn from.

Originality/value - Sustainability research, practice and education generally focuses on structural or systemic factors of transformation (e.g. technology, governance and policy) without due consideration as to how institutions and systems are shaping and shaped by the transformation of personal agency and subjectivity. This presents a vast untapped and under-studied potential for addressing deep leverage points for change by using a relational approach to link personal, societal and ecological transformations for sustainability.
\end{abstract}

Keywords Sustainability education, Systems thinking, Anti-oppression pedagogy, Contemplative pedagogy, Eco-justice, Relational ontology

Paper type Case study

(C) Zack Walsh, Jessica Böhme, Brooke D. Lavelle and Christine Wamsler. Published by Emerald Publishing Limited. This article is published under the Creative Commons Attribution (CC BY 4.0) license. Anyone may reproduce, distribute, translate and create derivative works of this article (for both commercial and non-commercial purposes), subject to full attribution to the original publication and authors. The full terms of this license may be seen at http://creativecommons.org/licences/by/4.0/ legalcode

The authors would like to thank Claire Whitmer and Olivia Bronson for contributing to the ecocourse curriculum. Thanks to Thomas Bruhn for providing feedback on drafts, and thanks to all who participated in the course.

Justiceoriented approach

Received 24 May 2020 Revised 11 July 2020 21 July 2020 Accepted 24 July 2020 
IJSHE

21,7

1588

\section{Introduction}

Given that the Earth-system is a complex adaptive system coupled with social systems, it is crucial that education programs support capacities for dealing with complexity, uncertainty, and transdisciplinarity to effectively address sustainability challenges (Schellnhuber, 2002; Schmuck and Schultz, 2002; Lang et al., 2012). Current mainstream education, however, tends to teach students to "think the world to pieces," through analysis, compartmentalization or reductionism (McInnis, 1972). In fact, today's educational policy and practices are rooted in modern ontological and epistemological traditions that reflect what Gregory Bateson referred to as an illusion of separation from nature (Bateson, 1982). The "modern curriculum" fragments "the world into bits and pieces called disciplines and subdisciplines" (Orr, 1991, p. 52). As a result, mainstream education typically fails to teach students how to understand and address the complexity of today's interrelated social and ecological problems.

Transformative learning was developed as a response to such shortfalls. It is learning that aims to transform our existential understanding of humanity, including interrelationships both among humans and between humans and non-humans and the fundamentals of wellbeing (Laininen, 2019). On this basis, it "aims at developing a holistic worldview and deep realization and coherence of the purpose, direction, values, choices and actions of one's life" (Laininen, 2019, p. 183). It is presumed to lead to the emergence of learning communities and ecosystems in which new lifestyles and more widespread cultural transformations can support sustainability in society (Laininen, 2019; Lange, 2018). This requires transforming how we relate to ourselves, to each other, to the environment and to the future (Wamsler and Restoy, 2020) [1].

At the same time, increasing experience with, and research on, transformative learning has also illustrated its limitations (Taylor and Cranton, 2013). Accordingly, scholars have increasingly suggested that relational modes of knowing (epistemology), being (ontology) and doing (ethics) would offer significant possibilities for revitalizing the field of transformative learning (Lange, 2018; Walsh et al., 2020). This need is supported by a growing body of scholars from various disciplines who emphasize that a broader cultural transformation towards sustainability requires a shift toward a relational paradigm (Walsh et al., 2020).

A relational shift is thus urgently needed to better orient transformative education towards sustainability, yet it has not so far been realized and related methods are lacking (Spretnak, 2011). Such a shift can be characterized as a turn toward a relational ethico-onto-epistemology, which Karen Barad refers to as a single tri-partite constellation that does not presuppose subject-object and nature-culture binaries (Barad, 2007). Although few examples exist (Netherwood et al., 2006; Mcphie and Clarke, 2019; Taylor and Pacini-Ketchabaw, 2019), relational approaches to sustainability and transformative education are under-studied and vastly under-employed (Walsh et al, 2020; Williams, 2013; Lange, 2018; O’Neil, 2018).

Relational approaches to transformative education are not only key to advance transformative learning, they also have the potential to support social justice goals (Lange, 2018). Social justice issues are important for transformational education to facilitate societal change and activate transformation towards sustainability (Tomlinson-Clarke and Clarke, 2016). However, social justice issues are often not adequately addressed in sustainable education (Bradley, 2009; Godfrey, 2015; Friesen, 2014). In spite of the fact that "social inequality and imbalances of power are at the heart of environmental degradation, resource depletion, pollution and even overpopulation" (Bullard and Chavis, 1993, p. 23), the role of individuals and the intertwined issues of justice and equity are still insufficiently addressed (Brechin, 2008; Lever-Tracy, 2010; O'Brien and Leichenko, 2019). Social-ecological transformation is in fact an intergenerational equity issue, including all people on this planet and future generations (Schneidewind, 2019). It should allow for people's flourishing now 
and into the future "whilst living within the limits of supporting ecosystems" (Agyeman et al., 2003, p. 5).

The EcoJustice course, which is assessed in this article, was developed to address current shortfalls in sustainability education. In fact, it was developed to foster transformative learning towards sustainability using a relational, justice-oriented approach. After a description of the methodology (Section 2), the assessment of its development (design and content) and impact are presented (Section 3), before we conclude with lessons learned and recommendations for curricula development that other universities/training institutions could learn from (Section 4).

\section{Methodology}

This article provides a reflexive case study of the EcoJustice course, which was developed during 2018-2019 and implemented during 2019-2020. More specifically, we assess the following three phases of its development and implementation:

\subsection{Phase I: development of the EcoJustice course}

The development of the EcoJustice course was the outcome of a broad consultation process between the Courage of Care Coalition in the United States and the A Mindset for the Anthropocene project at the Institute for Advanced Sustainability Studies (IASS) in Germany. It was informed by a series of five workshops and a literature review. The workshop participants were identified through a targeted selection of scholars and practitioners and an open call for participation related to the themes of this paper. The workshops included a total of 125 participants [2].

For the literate review, the literature was selected based on an exploratory approach, combining the use of scholarly database searches with input from the consultation process, the associated five workshops and following continuous communication with participants [3]. The latter was also supported through the participatory development of a web-based communication platform and database in the field between 2017 and 2019. The process resulted in the identification of a total of 100 publications for analysis. The assessment of this phase provided critical input for the course development process and the resultant curriculum of the first prototype. More specifically, it provided the scientific knowledge base and the identification of current gaps in sustainability research, practice and education which the course was based on.

\subsection{Phase II: prototype in Ratna Ling}

The goal of the second phase was to implement the first prototype via in-person education, and to experiment with various practices that were developed to foster a relational paradigm. It was implemented during a 2.5-day workshop from August 14th to August 16th, 2019 at the Ratna Ling retreat center in California, USA. Participants were selected and invited by invitation-only based on their expertise in areas relevant to the course. They included contemplative scholar-practitioners, equity and systems change workers, activists, and sustainability scholars.

The overall purpose of the prototype implementation was to deepen our understanding of the impact and effectiveness of the developed content and practices and to learn from other practitioners. The assessment of this phase was based on participatory observation, two group discussions and a follow-up survey (Table 1). This way, participants could provide different input and experiences that helped rapidly crowdsource feedback to enhance the course. Among the 17 participants, there were: 9 males, 8 females; 14 North 
IJSHE

21,7

\section{0}

SEE

HEAL

ACT

\section{Table 1.}

Leading questions for group discussions for each capacity: love, see, heal, envision, act
LOVE $\quad$ How do you experience the non-separation between inner and outer ecology?

- What, if any, practices or traditions have informed your own relational approach and understanding?

- How do you sense your intrinsic relationships with the web of life and life processes (e.g. plants, animals, minerals, water, etc...)?

- How do you sense your disconnection?

- How can we build care-based systems and structures that enhance the 'quality' of our relationships (to each other, to non-humans, to life cycles, etc. . .)?

- What is the history of people's relationships to the environment in which you live?

- Try mapping some place-based connections to your bioregion or community. How you are situated in the urban/rural ecology around you?

- How does un/sustainability shape subjectivity (e.g. our ways of experiencing, relating, and being in the world)?

- How does your way of being in the world reproduce the underlying histories, patterns and dynamics of un/sustainability?

- How do you experience the differential impacts, responsibilities and experiences of those suffering from various social-ecological crises?

- How does your privilege (class, race, gender), biases, etc. . inform your experience?

- What is your experience with the seven stages of grief? Where do you get stuck?

- How have you internalized systems of eco-crisis?

- How are your experiences and relationships informed by an industrial growth paradigm?

- How is this related to other systems of oppression?

- Consider your stress shapes and conditioned tendencies: How have they served you? What is their shadow side? Could you meet your underlying needs in healthier, more sustainable ways?

ENVISION • What do you think the future will be like?

- What are the hidden assumptions of your vision of the future?

- How are your hidden assumptions informed by your culture (e.g. ideas about gender, nature and technology, values and traditions, etc. . .)?

- What is your preferred future? How might you get there?

- Are there ways to orient yourself more clearly toward your preferred future?

- Take a personal inventory and/or community assessment of your strengths and weaknesses. Can you identify the boundary conditions, constraints and conditions of support for taking effective action?

- When is it more or less appropriate to reform, resist or create alternatives?

- What are your unique personal capacities to affect transformation based on your skills, experiences, talents, privileges, social networks, etc. ..?

- What relationships empower you to affect change, given your individual role and circle of influence?

Americans, 2 Europeans and 1 Asian; 7 spiritual activists and contemplative practitioners, 6 university professors in relevant fields and 4 sustainability researchers.

\subsection{Phase III: online course at Lund University Centre for Sustainability Studies}

Based on the results from Phase II, the EcoJustice course was turned into an online course and then tested in the context of a Master's Program on Environmental Studies and Sustainability Science at the Lund University Centre for Sustainability Studies in Sweden. More specifically, the EcoJustice course was implemented as an obligatory component of the master's level course on "Sustainability and Inner Transformation". The course took place from November 2019 to January 2020, including 24 students.

Data was collected during the course period (from online discussion platforms) and afterwards through in-class group discussions and a follow-up survey (Table 2). Among the 24 participants, there were: 18 females, 6 males; 12 Europeans, 5 Asians, 4 Latin Americans 


\begin{tabular}{|c|c|c|}
\hline Logic and flow of modules & $\begin{array}{l}\text { - Did the underlying logic and flow of the sessions (love, see, heal, } \\
\text { envision, act) support your learning? }\end{array}$ & $\begin{array}{l}\text { Justice- } \\
\text { oriented }\end{array}$ \\
\hline Presentations and practices & $\begin{array}{l}\text {-What were related strengths and weaknesses? } \\
\text { - How did the presentations and practices resonate with you? } \\
\text { - What were their strengths and weaknesses? } \\
\text { - What was particularly helpful for you? }\end{array}$ & approach \\
\hline $\begin{array}{l}\text { Personal, social and ecological } \\
\text { dimensions }\end{array}$ & $\begin{array}{l}\text { - How did you experience the interrelation between personal, social, and } \\
\text { ecological transformation? } \\
\text { - How well did we integrate these aspects to link inner and outer }\end{array}$ & 1591 \\
\hline Gaps and blind spots & $\begin{array}{l}\text { transformation? } \\
\text { - Did you feel at any point that something was missing for you? } \\
\text { - What would you like to add or change? } \\
\text { - Were there things you did not feel comfortable sharing? } \\
\text { - How could this be addressed by the course/ online format? }\end{array}$ & \\
\hline Follow-up and future work & $\begin{array}{l}\text { - What question(s) are you sitting with after the online course? } \\
\text { - How do you plan to integrate the learnings of the course in your daily } \\
\text { work? }\end{array}$ & $\begin{array}{r}\text { regarding the } \\
\text { implementation } \\
\text { process }\end{array}$ \\
\hline
\end{tabular}

and 3 North Americans. Finally, the empirical results from phases II and III were also compared to existing literature to validate identified patterns.

\section{Results}

\subsection{Results Phase I}

Because of the fact that the course was aimed to address current shortfalls in sustainability education and transformative learning (Section 1), the development of the curriculum (and its relational, justice-oriented approach) required a broad consultation process and a critical review of current knowledge and approaches. In fact, to be able to apply relational approaches to transformative education, we first needed to identify what these relational approaches in the context of sustainability consist of.

The results of the broad consultation process and review (Section 2) were peer-reviewed and published (Walsh et al., 2020), and were key for the curriculum development. They influenced: the development of the content of the different course modules, the selection of related practices and the establishment of cooperation with practitioners and scholars in the field, which was important for the following phases II and III (Section 3.2). In fact, the established cooperation ensured for instance the successful implementation of phases II and III through the identification of relevant participants for the first prototype implementation and the testing of the online version in cooperation with Lund University (Section 3.2).

The identified relational modes of knowing (epistemology), being (ontology) and doing (ethics) in the context of sustainability (Walsh et al., 2020), which in the following guided the curriculum development, were defined as follows:

- Relational epistemologies acknowledge the observer's role in shaping knowledge and call for transdisciplinary, intersectional and diffractive (nonrepresentational) methods to ensure the integration of different ways of knowing for sustainability.

- Relational ontologies posit that no entity preexists the relations that constitute it. All entities emerge out of their constitutive relations. Personal and socio-natural processes are mutually entangled and co-shaping sustainability.

- Relational ethics describe non-anthropocentric perspectives about which actions are conducive to human-non-human flourishing as an essential aspect of sustainability. 
IJSHE 21,7

To identify the most adequate teaching methods regarding these relational approaches towards sustainability and to ensure a justice lens, during the consultation process it was also decided to co-develop the curriculum with the Courage of Care Coalition, because of its extensive experience with transformative learning to support social justice. Courage of Care has developed a social movement-based strategy that aligned well with the ideas of the EcoJustice course. It aims to help individuals and organizations develop compassionate, just, and equitable communities of practice ( $\mathrm{CoPs}$ ) through training in relational care practices (loving), anti-oppressive pedagogies (seeing), restorative healing tools (healing), visionary and artistic tools (envisioning) and systems thinking (acting). These five core capacities are taught iteratively using a modular approach (Table 3). Whilst we kept the same modular approach, the content of each module was further developed to address current gaps in sustainability research, practice and education.

The key learning objective of the LOVE module was defined to deconstruct natureculture dualisms and develop a systems view of life that views ecology as a web of interrelationships. Love is foundational to the overall course, as it forms the basis of the relational approach that informed each module. Given that the field of transformative learning and sustainability education critiques the lack of relationality in mainstream education, the love module is about reclaiming relationality as a foundational principle and approach to education. Love was defined as an active stance of care. The love module taught (knowing) how a sense of separation and dualism underlies historical and current social and ecological injustices and how love-based activism (doing) provides more equitable social and material conditions for human-Earth flourishing. In addition, contemplative practices for extending care, receiving care and practicing deep self-care were used to cultivate love (being) as an active stance of care. This first module links to other research and competency frameworks for transformative skills, which have highlighted the importance of compassion and empathy for sustainability (Glasser and Hirsh, 2016; Sterling et al., 2017; Wamsler, 2019; Wamsler et al., 2020; CCCE, 2019).

The key learning objective of the SEE module was defined to develop the capacity to see the complexity and intersectionality of multiple converging crises. It considered the breakdown of ecological systems as effectuated by the breakdown of interlocking personal and social sub-systems. It identified six of the underlying systems driving eco-crisis capitalism, anthropocentrism, patriarchy, militarism, colonialism and white supremacy. Students were taught to understanding (knowing) their intimate relations to eco-crisis by considering the mundane ways they communicate, the values they have and the daily choices they make within such systemic contexts. Contemplative and somatic practices (being and doing) helped participants to explore their coping and protective strategies under stress. By becoming more aware of their stress responses, they developed an increasing capacity to tolerate complexity and also to respond to and address systems of domination and oppression that exacerbate the climate crisis in more just and sustainable ways.

The key learning objective of the HEAL module was defined to facilitate restorative and reparative processes internally, between communities, and with our world. Part of this involves helping people heal from the pain and trauma of the eco-crisis. It also includes helping people understand (knowing) that healing will also require restoration of land, redistribution of resources and protections for communities most affected by sustainability crises. Contemplative practices (being) were used to introduce participants to collective approaches for healing grief. Healing was also presented as requiring not just personal work but also social and political responses creating shifts in ourselves and societies. The module thus not only encouraged stopping harm at its source but also encouraged participants to cultivate regenerative, care-based relationships and care-based systems (doing). 


\begin{tabular}{|c|c|c|c|c|}
\hline & Knowing (lecture) & Being (experience) & Doing (skills) & \\
\hline LOVE & $\begin{array}{l}\text { - Understand how modern } \\
\text { concepts of "Nature" are } \\
\text { based on a fundamentally } \\
\text { flawed sense of separation } \\
\text { and dualism } \\
\text { - Understand how this sense } \\
\text { of separation and dualism } \\
\text { underlies historical and } \\
\text { current social and ecological } \\
\text { injustices } \\
\text { - Develop an alternative } \\
\text { systems view of life that } \\
\text { views ecology as a web of } \\
\text { inter-relationships } \\
\text { - Consider how this systems } \\
\text { view could provide more } \\
\text { equitable social and } \\
\text { material conditions for } \\
\text { flourishing in the face of } \\
\text { crises }\end{array}$ & $\begin{array}{l}\text { - Cultivate a non-dual field } \\
\text { awareness of inner and outer } \\
\text { ecology } \\
\text { - Gain a vital appreciation for } \\
\text { life and life-giving processes } \\
\text { as sacred } \\
\text { - Reconnect to love as the } \\
\text { ground for being in right } \\
\text { relationship with others } \\
\text { - Cultivate a renewed sense of } \\
\text { intimacy with nature } \\
\text { - Sense one's intrinsic } \\
\text { relationships to the web of } \\
\text { life and life processes (e.g. } \\
\text { plants, animals, minerals, } \\
\text { water, etc...) }\end{array}$ & $\begin{array}{l}\text { - Develop skills to extend } \\
\text { and receive care to non- } \\
\text { humans (animals, plants, } \\
\text { etc. ..) } \\
\text { - Develop skills that center } \\
\text { and foster reciprocity and } \\
\text { co-creation of meaning }\end{array}$ & approach \\
\hline SEE & $\begin{array}{l}\text { - Understand the complexity } \\
\text { of today's ecological } \\
\text { challenges and their socio- } \\
\text { historical-cultural- } \\
\text { psychological roots } \\
\text { - Develop intersectional } \\
\text { analyses of sustainability } \\
\text { issues that include social } \\
\text { and ecological justice lenses } \\
\text { - Understand sustainability } \\
\text { from multiple perspectives } \\
\text { and social sectors } \\
\text { - Learn various methods for } \\
\text { systematically } \\
\text { understanding the } \\
\text { complexity and diversity of } \\
\text { perspectives and } \\
\text { experiences }\end{array}$ & $\begin{array}{l}\text { - Become aware of how you are } \\
\text { situated in the urban/rural } \\
\text { ecology around you, including } \\
\text { the ways in which your } \\
\text { privilege (class, race, gender), } \\
\text { biases, etc... inform your } \\
\text { experience } \\
\text { - Map place-based connections } \\
\text { to your bioregion/community. } \\
\text { What is the history of people's } \\
\text { relationships to the } \\
\text { environment in which you } \\
\text { live? } \\
\text { - Become aware of how your } \\
\text { way of being in the world } \\
\text { reproduces the underlying } \\
\text { histories, patterns, and } \\
\text { dynamics of un/sustainability } \\
\text { - Experience how } \\
\text { un/sustainability shapes } \\
\text { subjectivity (e.g. our ways of } \\
\text { experiencing, relating, and } \\
\text { being in the world)? } \\
\text { - Reflect on the differential } \\
\text { impacts, responsibilities, and } \\
\text { experiences of those suffering } \\
\text { from related social-ecological } \\
\text { crises }\end{array}$ & $\begin{array}{l}\text { - Develop experience-based } \\
\text { competencies for systems } \\
\text { thinking }\end{array}$ & \\
\hline HEAL & $\begin{array}{l}\text { - Understand the physical and } \\
\text { mental impacts of ecological } \\
\text { crises } \\
\text { - Learn about habituated and }\end{array}$ & $\begin{array}{l}\text { - Metabolize and transform } \\
\text { negative responses to } \\
\text { ecological trauma (e.g. } \\
\text { denial, grief, anger) and }\end{array}$ & $\begin{array}{l}\text { - Practice tools for healing } \\
\text { any fundamental rupture, } \\
\text { separation or disconnection } \\
\text { to life } \\
\text { (continued) }\end{array}$ & $\begin{array}{r}\text { Table } 3 . \\
\text { Overview of the } \\
\text { course's logical steps } \\
\text { and learning } \\
\text { objectives }\end{array}$ \\
\hline
\end{tabular}




\begin{tabular}{|c|c|c|c|}
\hline & Knowing (lecture) & Being (experience) & Doing (skills) \\
\hline & $\begin{array}{l}\text { automatic personal and social } \\
\text { patterns driving } \\
\text { unsustainability (e.g. } \\
\text { consumerism, addictions, } \\
\text { transgressions, burnout) } \\
\text { - Learn how to transform } \\
\text { unsustainable into } \\
\text { sustainable patterns }\end{array}$ & $\begin{array}{l}\text { separation from nature (e.g. } \\
\text { psychoterratica) } \\
\text { - Experience ourselves in } \\
\text { compassionate relation to } \\
\text { human and non-human } \\
\text { others } \\
\text { - Transform negative } \\
\text { emotions into constructive } \\
\text { responses to eco-crisis } \\
\text { - Exercises that scaffold } \\
\text { healing from the trauma of } \\
\text { ecological suffering }\end{array}$ & \\
\hline ENVISION & $\begin{array}{l}\text { - Understand that current } \\
\text { archetypes, cultural } \\
\text { assumptions, values and } \\
\text { systems that we take as given } \\
\text { are socio-historically } \\
\text { conditioned and subject to } \\
\text { change } \\
\text { - Imagine many possible futures } \\
\text { and envision futures from the } \\
\text { standpoint of the cultural } \\
\text { heritage, values, systems etc... } \\
\text { that one aspires to express } \\
\text { - Understand the baseline } \\
\text { criteria for a sustainable, } \\
\text { ecological civilization and } \\
\text { become familiar with } \\
\text { sustainable alternatives that } \\
\text { meet these criteria }\end{array}$ & $\begin{array}{l}\text { - Practice dialogical, reflective, } \\
\text { and arts-based exercises that } \\
\text { express the aesthetics of } \\
\text { sustainable futures } \\
\text { - Narrative storytelling } \\
\text { exercise }\end{array}$ & $\begin{array}{l}\text { - Develop a short-, medium- } \\
\text { and long-term perspective } \\
\text { on change } \\
\text { - Cultivate positive } \\
\text { potentials in the midst of } \\
\text { suffering }\end{array}$ \\
\hline ACT & $\begin{array}{l}\text { - Understand current } \\
\text { movements and just } \\
\text { strategies that support the } \\
\text { movement to sustainability } \\
\text { - Understand our individual } \\
\text { roles/circle of influence. } \\
\text { What relationships (dis) } \\
\text { empower our capacity to } \\
\text { affect change? } \\
\text { - Assess strategic leverage } \\
\text { points for taking action } \\
\text { toward sustainability }\end{array}$ & $\begin{array}{l}\text { - Explore our unique personal } \\
\text { capacities to affect } \\
\text { transformation based on our } \\
\text { skills, experiences, talents, } \\
\text { privileges, social networks, } \\
\text { etc... }\end{array}$ & $\begin{array}{l}\text { - Develop skills to align } \\
\text { sustainable values and } \\
\text { attitudes with sustainable } \\
\text { behaviour } \\
\text { - Develop a personal and/or } \\
\text { community strategy for } \\
\text { change } \\
\text { - Build the relationships, } \\
\text { systems and structures that } \\
\text { support life's flourishing } \\
\text { - Take a personal inventory } \\
\text { and/or community } \\
\text { assessment of your strengths/ } \\
\text { weaknesses and opportunities } \\
\text { for change }\end{array}$ \\
\hline
\end{tabular}

Table 3.

The key learning objective of the ENVISION module was to inspire new narratives that imagine viable pathways toward a socially just and sustainable future. Plausible futures arise out of a combination of the past, present, and future. Students were taught several archetypal ways to understand the future (i.e. evolutionary progress, social collapse, Gaia, globalism and retro-futurism). Climate fiction (or cli-fi) was presented as a genre of speculative fiction to illustrate and reflect about visions of the future impacted by climate 
change. Participants learned (knowing) about alternative visions of the future, emerging in speculative fiction sub-genres such as the new weird, solarpunk, indigenous futurism, afrofuturism and sinofuturism. Centering, presencing and visioning practices were used to deepen participants' experiences of climate-related suffering (being), and the possibility for deeply transformative action (doing). The second, third and fourth module link to research and competency frameworks for transformative skills, which have highlighted the importance of openness, self-awareness, self-reflection and perspective-seeking for sustainability (Glasser and Hirsh, 2016; Sterling et al., 2017; Wamsler et al., 2020; CCCE, 2019).

The key learning objective of the ACT module was to describe, assess and move to implement strategies for a just transition. Students were introduced to three logics of transformation: reform, resist and build alternatives. They learned (knowing) how sustainability is practiced via lifestyle changes, spiritual and community preparations, socio-technical transitions and social and environmental movements. Such transformative practices were also discussed in the context of strategies for systems change. Six important political trends were introduced: eco-socialism, eco-civilization, social anarchism, the commons, degrowth and buen vivir. Contemplative and reflective practices (being) were used to take stock of participants' current spiritual and practical approaches to climate preparedness and systems change. Students concluded by considering how the communities they engage with can meaningfully contribute to a just transition (doing). The last module links to research and competency frameworks for transformative skills, which have highlighted the importance of agency, sense-making and values-based courage and engagement for sustainability (Glasser and Hirsh, 2016; Sterling et al., 2017; Wamsler et al., 2020; CCCE, 2019).

The diagnostic logic that informs Courage of Care's theory of change was useful for the course development as it is applicable and relevant across contexts. The five-module structure allowed participants to understand the relational nature of eco-crisis (LOVE), its roots (SEE), how to address them (HEAL), what alternatives to create (ENVISION) and what pathways can guide transformation (ACT). Within the five modules, the content and practices were further developed based on the relational modes of knowing (epistemology), being (ontology) and doing (ethics) identified by Walsh et al. (2020) as relevant to the context of sustainability.

The greatest challenge of the curriculum development process (results Phase I) was to develop the curriculum in a way that addressed the diverse knowledge and needs of different participants. Sustainability practitioners less familiar with certain sustainability dimensions (personal, societal, ecological) and contemplative and relational practices often needed more support processing their experiences (being) and aligning them with their practice (doing); whereas contemplative practitioners often needed more support understanding the complexity of the eco-crisis and aligning this understanding (knowing) with their practice (doing).

Future iterations of the curriculum could better meet participants' needs if different versions were developed to scaffold learning according to specific developmental trajectories. However, for the next phase, it was decided to keep a balance that was seen as adequate for a broad audience.

\subsection{Result Phases II and III}

The second and third phases focused on prototyping and implementing the course to assess the impact of using a relational, justice-oriented approach on transformative learning towards sustainability. Through the participatory observation, group discussions and 
IJSHE 21,7

\section{6}

survey, we could identify what helped the participants to understand and experience relationality (Section 3.2.1) and social justice (Section 3.2.2).

3.2.1 Relationality. In sum, the aspects that helped participants most to understand and experience relationality through the course's content and design were related to issues of:

- embodied learning;

- human-nature connectedness;

- place-based learning; and

- handling uncertainty.

Embodied learning: Most participants highlighted the importance of linking the provision of information and facts with embodied approaches and practices. In fact, each module started out with a lecture, followed by individual contemplative and somatic practices and reflective group exercises. In this way, knowledge coming from sustainability science, psychology, philosophy and transformation theories were integrated using embodied practices. Contemplative practices that were particularly relevant included compassionate presence to feelings, arts-based practices and the three modes of care (extending care, receiving care and deep self-care). The three modes of care comprise the relational model of compassion, also known as sustainable compassion training, that Courage of Care utilizes in its approach (Condon and Makransky, 2019; Lavelle, 2017).

To experience relationality, the participants affirmed research that states that reconnecting to one's self, others and the environment requires not just a cognitive, but also an embodied shift. Embodied cognition suggests that the body is often disregarded as an integral part of knowledge generation, especially in higher education (Eaton et al., 2016). This is unfortunate as the separation of mind and body is also said to be one important reason for unsustainable behaviour (Eaton et al., 2016). Transformation thus requires one not only to think differently, and is hence not merely an epistemological process, but as we noted in the beginning, also an ontological and ethical process.

Our results also showed that experiencing relationality may feel unfamiliar and challenging for course participants. Not only might one struggle to develop related emotions but also to communicate relationality, given that so much of our world is siloed. As Lakoff notes, our language determines how we think and feel (Lakoff, 2008) and is embedded in current cultures and structures. One participant, for example, asked:

How can I use this knowledge within my work environment, especially if it is dominated by a corporate culture?

Such difficulties illustrate the need for embodying and teaching new ways of being (and their linkages to societal and ecological transformation) as a part of transformative education (Daloz, 2004; Lange, 2004; Kollmuss and Agyeman, 2002), which the course achieved. A participant noted, for instance:

It was very new to me to do these kinds of practices, but to me, this was the most important during the workshop.

Another participant said:

So many of the practices were beneficial and helped to create a deep context of trust and intimacy.

Human-nature connectedness: The course supported in-depth reflections regarding humannature connectedness. These included a collective meditation on the natural elements (earth, wind, water, fire) in our surroundings, their embodiment in each of the participants' 
physical bodies, and the inter-relation between those elements in their bodies and environments. The lectures presented information on how the systems view of life helps explain the interconnectedness of personal, social, and ecological systems, in contradistinction to dualistic views that objectify and reify nature as distinct from culture. Many participants highlighted the importance of such input. As stated by one participant:

Justice-
oriented
approach

1597

It is not often easy to relate [personal, social, and ecological systems] generically but when I think of particular contexts then it seems much easier to relate them [ . . . ] I believe these intercrossings between practical and theoretical, pragmatic and spiritual and inner and outer are a good starting point for [post-dualistic conceptualizations] to emerge.

Nonetheless, although the course referenced ways "nature" was historically tied to modern dualism and was reformulated along the lines of post-dualistic conceptualizations of inner and outer ecology (Morton, 2009; Puis de la Bellacasa, 2017), group discussions revealed that some participants persistently framed nature using the language of separation. For example, participants used language such as:

[... ] being "in" nature, connecting "to" nature, and watching nature.

Overcoming this inner-outer binary often requires developing a new language, such as used by David Abram, who dissolves the dichotomy between nature and culture by referring to it as the human and more-than-human-world (Abram, 1996). As Bollier and Helfrich (2019) and Schaef (1987) note, overcoming the many forms of resistance to relationality in our culture requires a new language, which we are only beginning to form.

In addition, around one-fourth of participants noted that when they were young, they felt more connected to the more-than-human-world and experienced less of a dichotomy. This is crucial because research shows that people who have experienced this strong connection while young are more likely in adult life to act sustainably. For example, people who grow up spending free-time in the more-than-human-world, such as green neighbourhoods, at a coast, or regular visits to green spaces, are more likely to take later actions that benefit the environment, such as recycling, buying eco-friendly products, and environmental volunteering (Alcock et al., 2020). Moreover, research indicates that exposure to the morethan-human-world is of importance for physical and psychological health, increasing one's ability to concentrate, improving one's academic performance and reducing one's stress (Faber and Kuo, 2006; Kaplan, 1995; Wells and Evans, 2003). However, our results showed that around one-fourth of participants felt rather indifferent to the more-than-human-world when they grew up. At the same time, it was reported that this changed through increased awareness while growing up. This shows, that even when not growing up with such access to green space, a shift to dissolve the dichotomy can come about through other means (including education).

One such possibility is by invoking feelings of awe, an aspect which also emerged from the course evaluation. The ability to be in awe is getting increased attention, especially in positive psychology, as it leaves one with a feeling of happiness and content (Bethelmy and Corraliza, 2019). Moreover, recent research also shows that the experience of awe leads to pro-social and pro-environment behaviours, such as changed consumption patterns (Griskevicius et al., 2010). Wang et al. (2019), for example, shows that the feeling of awe increases green consumption (defined as consumption behaviour aimed at conserving resources and protecting the environment). Another study shows that people who experience awe become less self-centered and more considerate of others and the broader external environment (Keltner and Haidt, 2003). More importantly, Wang et al. (2019) suggest that awe in relation to nature increases the feeling of interconnectedness, because it 
IJSHE 21,7

encourages individuals to pay more attention to others and the natural environment, it makes people feel that they are no longer isolated individuals, but closely connected to other humans and non-humans and it enables people to see themselves and the world from a different angle, emphasizing their participation within a larger whole (Wang et al., 2019).

Several statements of participants indicated how the course has helped to spur feelings of awe and facilitate an associated increase in compassion to one's self, others and the environment. For example, one participant noted:

Connecting with other forms of life gives me a great sense of humility, which I believe is very much needed in our times of human hubris. However, when caught up in my daily life, with the habits and sometimes stressful tasks, it is easy for me to forget this constant relationship with others and nature. Therefore, I believe it is important to take time every day to remind ourselves of this connection. In that regard, the exercises around care provided in this lecture have been very helpful to me.

The feeling of awe arises when people encounter something that is beyond their current way of knowing, provoking a need to update their mental schemas (Keltner and Haidt, 2003).

Place-based learning: Another aspect that was frequently highlighted by the participants as helpful for understanding and experiencing relationality was related to context and placebased learning. These were addressed through different lectures and practices, including land acknowledgements and nature wandering practices. Participants asked permission to interact with other beings in nature, practiced sensing their inter-relatedness to other beings and made them offerings.

Some participants noted that context is important in determining whether they feel connected with the more-than-human-world or not. Participants noted for instance that it was easy to forget the more-than-human-world in an urbanized environment and to disregard topics such as climate change, if it seems invisible in their everyday environment. For example, one participant noted:

I believe this type of mental disconnection with my surroundings contributes to blur the consequences of my actions on the environment around me. This aspect is reinforced by the fact that I personally do not directly suffer from these consequences.

This is in line with research on transformative learning approaches, which increasingly acknowledge the necessity of place-based learning, grounded in the relationship between place and people (Lange, 2019; Pisters et al., 2019). Several studies describe the value of appreciating the cultural, historical, and traditional connections between people and natural resources (Armitage et al., 2008; Bowers, 2005). Especially, as colonialism has disconnected people from the unique cultures that emerged in specific places (Battiste et al., 2005). As such, it is especially important to engage in place-based practices to address wealth and power disparities, resulting from colonialism, and it is important to recognize the damage that has been done to the land (Williams, 2018). Williams (2018) states that a relational shift remains only partial if the relation between place and people is not acknowledged (Williams, 2018).

Handling uncertainty: The framing of the course was oriented around two futures: the Great Transition and the Great Unraveling. The Great Transition describes a future in which society is comprehensively reorganized to sustain itself in dynamic equilibrium with the Earth's systems. The Great Unraveling describes a future in which society's population and complexity have grown beyond its capacity to sustain itself. Both these visions hold a certain truth, as both are already happening. The challenge is to stay attuned to both truths - to help people adapt to near-term social collapse, while cultivating the positive 
potentials of the Great Transition (Walsh and Lavelle, 2019; Walsh, 2020; Pihkala, 2018; Noorgaard, 2011).

The difficulty of dealing with the uncertainty of both futures was apparent during the workshops. Around two-thirds of the participants in the online course felt caught in between the two narratives. One-third tended to see a pessimistic future as more likely, and only around $10 \%$ explicitly leaned towards a more optimistic view. Interestingly, on all sides, people were aware of their tendencies to be rather optimistic or pessimistic.

Optimism can be distinguished between realistic and unrealistic optimism (Peterson, 2000). Realistic optimism can be very helpful, whereas unrealistic optimism can reinforce positive delusions that create suffering. If optimism is imposed, it can also encourage negative self-reflection, denial and dissatisfaction (Seligman, 1990). If there is no realistic hope, it is difficult to act. Research in positive psychology shows that people need a sense of manageability to take care of things (Antonovsky, 1987).

A relational approach to transformative sustainability education might distance itself from the idea of predefined goals, outcomes and actions, which is dominant in sustainability education. When taking action towards sustainability, the basic assumption is that sustainability can be controlled and managed. According to the philosopher Donna Haraway though, strings are always attached and we always become-with (Haraway, 2015). To become-with means that we are not pre-given, autonomous individuals who can act upon sustainability. Instead, we act and emerge with it. Our own agency emerges through the intra-action with what we are dealing with. Nothing exists outside of or prior to its relations with others and agency is not possessed by a single entity, but emerges through relationships (Barad, 2007; Haraway, 2015). Hence, concrete outcomes for action cannot be predefined, but rather emerge (Verlie, 2018).

As a lot of the participants were either pessimistic or oscillated in between optimism and pessimism, it seems important to include further exercises to evoke feelings of manageability. This might include linking education more to active engagement, to a practice of change, as research suggests that people that do take action often feel more empowered and less overwhelmed (Stoknes, 2015; Sharma, 2017).

3.2.2 Social justice. In sum, the aspects that helped participants to understand and experience social justice through the course's content and design were related to issues of

- intersectionality; and

- CoPs.

Intersectionality. Several participants shared how their understanding and experience with sustainability was shaped by intersectionality. Intersectionality, first identified by Crenshaw (1989), reveals how individuals and groups relate differently based on their positionality. One's relation to climate change, for example, may differ because of their positionality within power structures, based on context-specific and dynamic social categorisations (Kaijser and Kronsell, 2014). One participant from Ghana, for instance, described how she grew up within a country with a high level of poverty and activities to survive, such as illegal mining, in which:

Forests are cleared and lost, waterbodies are destroyed with chemicals, and livelihood is eventually lost in the quest to survive.

She acknowledged the intersectional nature of the problem, as it is:

Related to the history and international politics of her home country. 
IJSHE 21,7

Moreover, participants reflected on how intersectionality could help inform their studies. One student, for example, wrote her final term paper on the topic of how intersectionality informed the participants' perspective and future work. As Boström et al. (2018) note, in academia, learning is still primarily taking place within disciplinary boundaries and often lacks intersectional perspectives. However, intersectionality can help people become more comfortable with “otherness" (O'Sullivan and Taylor, 2004), it can support epistemological justice, and it is especially relevant for addressing justice issues and for ensuring the adaptability of societies (Swanson et al., 2010).

Transformative learning is still in an experimental and exploratory phase and therefore benefits from including various forms of knowledge without evaluating one form of knowing over the other (Lange, 2019). To foster epistemological justice, multiple perspectives can be explicitly invited into the classroom, for example, through audio and visual media.

The content of our curriculum, for instance, intentionally centered marginalized perspectives by exploring alternative speculative fiction sub-genres such as afrofuturism, sinofuturism and indigenous futurism, which was appreciated by the students. Moreover, the course used intersectional methods to present the eco-crisis as a byproduct of interlocking systems of oppression and domination, in line with Freirian approaches to pedagogy and justice (Freire, 1993).

Epistemological diversity was further supported through the course by positioning the teacher as a co-learner who acknowledges the experience and knowledge of each of the participants. Each person was acknowledged as having something to contribute, rather than presuming that one person (the teacher) has all the answers. This aligns with Lange's suggestion to position the teacher more as a co-learner to flatten hierarchies and to allow for experiences of democracy in transformative education (Lange, 2004).

Communities of practice. To move toward action, participants pointed out repeatedly that they enjoyed and appreciated having a group of supportive and like-minded people to learn and practice with. The feedback showed that most participants work mostly by themselves and often feel left alone with their concerns, thoughts and ideas. There was common agreement that relationships were formed through the curriculum. As one participant noted:

Real relationships were formed that will lead to action and collaboration.

Participants also noted, that because of the trust that was formed within the group, they felt safe to articulate concerns and to be themselves.

The importance of so-called CoPs is increasingly acknowledged in the sustainability discourse as well as within the field of transformative learning (Murray and Salter, 2014). CoPs are based on the work of Wenger et al. (2002) and defined as "a group of people who share a concern, a set of problems, or a passion about a topic and who deepen their knowledge and expertise in this area by interacting on an ongoing basis" (Murray and Salter, 2014, p. 4). CoPs are shown to be especially relevant to sustain change in the longterm (Bradbury and Middlemiss, 2014). This is also important to approach interlocking crises from multiple perspectives, as CoPs can help us notice and tend to blind spots (Patten, 2018).

\section{Conclusions}

The purpose of this case study was to increase knowledge on how transformative learning towards sustainability can be fostered by using a relational, justice-oriented approach. Despite recent advancements in transformative education towards sustainability, current practices have not fully taken advantage of the potential of relational ways of knowing, 
being and doing (Lange, 2018; Walsh et al., 2020). The EcoJustice course demonstrates possible pathways as to how this could be done. The lessons learned from its development and implementation show that embracing a relational and justice-oriented approach is possible and that it can support the important emotional, cognitive, and relational competencies needed for linking personal, societal and ecological transformations. They influence embodied learning, human-nature connectedness, sense of place, intersectionality, the handling of uncertainty, as well as CoPs. The identified competencies and associated impacts provide important input for further developing competence-based approaches to education for sustainability, which are often limited by some of its failures to represent their transformative aspects (Glasser and Hirsh, 2016; Sterling et al., 2017; Wamsler et al., 2020)

Putting these different features into practice can be a challenging endeavor, and especially in traditional, bureaucratic educational structures [4]. It requires surpassing the limits of cognitive learning using emotional and experience-based learning methods that link theory and practice to foster sustained behavioural changes (Fugate et al., 2018). It also requires acknowledging that people of different social and cultural backgrounds have very different access points to this type of pedagogy. Experimental approaches such as the one taken in this case study show potential pathways forward. As Lange (2004) suggests, we are all learners in this. Teachers and facilitators should acknowledge that they are co-learners to promote the autonomy of students and encourage them to explore the ways they are related to other humans and non-humans. Although there is a broad spectrum of potential learning outcomes within transformative education, they are often aimed at cognitive and noncognitive changes enabling transformative actions.

However, relational, justice-oriented approaches should not be bound to specific outcomes, as effective outcomes towards sustainability are always emergent. Supporting the emergence of new approaches and solutions, it seems particularly important to implement courses that also support CoPs through associated structures (such as online networks, forums, continuous face-to-face or online encounters).

This case study provides important insights for further investigating the potential advantages and obstacles of a relational, justice-oriented approach to transformative sustainability education. Although relational approaches are increasingly acknowledged as a critical component towards sustainability (Walsh et al., 2020), it is important to critically engage how they may be used to encourage sustainable transformations.

Our results present a concrete process, methodology and practices, together with supportive features that can support the development of related training programs and courses. The practices and features identified have been used within education previously, yet this case study shows the possibility of linking them to relational approaches and social justice issues, offering promising pathways for further developing transformative education for sustainability that other universities/training institutions could follow or learn from.

\section{Notes}

1. Transformative learning, also called transformational learning, was developed by Jack Mezirow in 1978. It was used to shift one's way of being in the world by shifting one's perspective and thus "affects personal understanding of ourselves, relationships with other people, ways of thinking, belief systems, responses to environment, and overall interpretation of the world" (Simek, 2012, p. 1). Transformative learning has most commonly been used in adult and higher education to shift from mere conceptual learning towards self-directed, experiential, practical and applied adult learning (Cranston, 2006). Using transformative learning theory to inform sustainability education was first recognised at the 8th International Transformative Learning Conference in 2009 (Lange, 2012). 
IJSHE 21,7

2. Workshop 1 took place from 14 Aug. 2017 to 15 Aug. 2017 at the IASS Potsdam, Germany, workshop 2 from 13 Aug. 2019 to 16 Aug. 2019 at Ratna Ling, workshop 3 from 9 Sept. 2019 to 12 Sept. 2019 at Neudenau, Germany, workshop 4 from 30 Sept. 2019 to 2 Oct. 2019 at the IASS Potsdam, Germany, workshop 5 from 9 Dec. 2019 to 12 Dec. 2019 at Duke Kunshan University, China. All workshops aimed at identifying the scientific knowledge base and the identification of current gaps in sustainability research, practice and education regarding the inner aspects of transformation.

3. For more information regarding the literature review, the list of identified publications and their analyses, please see Walsh et al. (2020).

4. During Phase III, the presented course was included into existing structures. For related discussions on how educators can develop strategies to deal with traditional and bureaucratic education structures to achieve change, please see Wamsler (2020).

\section{References}

Abram, D. (1996), The Spell of the Sensuous, Vintage.

Agyeman, J., Doyle, R. and Evans, B. (2003), Just Sustainabilities: Development in an Unequal World, MIT Press, Boston.

Alcock, A., White, P., Pahl, S., Duarte-Davidson, R. and Fleming, L. (2020), “Associations between proenvironmental behaviour and neighbourhood nature, nature visit frequency and nature appreciation: Evidence from a nationally representative survey in England", Environment International, Vol. 136, pp. 105441, doi: 10.1016/j.envint.2019.105441.

Antonovsky, A. (1987), Unravelling the Mystery of Health, Jossey-Bass, San Francisco.

Armitage, D., Marschke, M. and Plummer, R. (2008), "Adaptive co-management and the paradox of learning”, Global Environmental Change, Vol. 18 No. 1, pp. 86-98.

Barad, K. (2007), Meeting the Universe Halfway: Quantum Physics and the Entanglement of Matter and Meaning, Duke University Press.

Bateson, G. (1982), Steps to an Ecology of Mind. Reprint 1987, Jason Aronson.

Battiste, M., Bell, L., Findlay, I., Findlay, L. and Henderson, S. (2005), "Thinking place: animation the indigenous humanities in education", The Australian Journal of Indigenous Education, Vol. 34, pp. 7-19.

Bethelmy, L.C. and Corraliza, J.A. (2019), "Transcendence and sublime experience in nature: awe and inspiring energy", Frontiers in Psychology, Vol. 10, pp. 509.

Bollier, D. and Helfrich, S. (2019), Free, Fair, and Alive: The Insurgent Power of the Commons, New Society Publishers, Gabriola Island, BC.

Boström, M., Andersson, E., Berg, M., Gustafsson, K., Gustavsson, E., Hysing, E., Lidskog, R., Löfmarck, E., Ojala, M., Olsson, J., Singleton, B., Svenberg, S., Uggla. and Öhman, J. (2018), "Conditions for transformative learning for sustainable development: a theoretical review and approach", Sustainability, Vol. 10 No. 12, p. 4479.

Bowers, C.A. (2005), "Is transformative learning the trojan horse of Western globalization? ”, Journal of Transformative Education, Vol. 3 No. 2, pp. 116-125.

Bradbury, S. and Middlemiss, L. (2014), "The role of learning in sustainable communities of practice", Local Environment, Vol. 20 No. 7.

Brechin, S.R. (2008), "Ostriches and change: a response to 'global warming and sociology", Current Sociology, Vol. 56 No. 3, p. 467-480.

Bullard, R.D. and Chavis, B., Jr (1993), Confronting Environmental Racism: Voices from the Grassroots, South End Press, Boston, MA. 
CCCE (2019), "The center for contemplative science and compassion-based ethics", Social, Emotional, and Ethical Learning, (SEE Learning), Emory University, Atlanta.

Condon, P. and Makransky, J. (2019), Recovering the Relational Starting Point of Compassion Training, A foundation for sustainable and inclusive care.

Cranston, P. (2006), Understanding and Promoting Transformative Learning, Jossey-Bass.

Crenshaw, K. (1989), Demarginalizing the Intersection of Race and Sex: A Black Feminist Critique of Antidiscrimination Doctrine, Feminist Theory and Antiracist Politics, University of Chicago Legal Forum.

Daloz, L.A. (2004), "Transformative learning for bioregional citizenship", in Learning toward an Ecological Consciousness: Selected Transformative Practices, Palgrave Macmillan US, New York, NY, pp. 29-45.

Eaton, M., Hughes, H. and MacGregor, J. (2016), Contemplative Approaches to Sustainability in Higher Education, Routledge.

Faber, T. and Kuo, F.E. (2006), "Is contact with nature important for healthy child development? State of the evidence", in Spencer, C., Blades, M., (eds). Children and Their Environments: Learning, Using and Designing Spaces, Cambridge University Press, Cambridge, pp. 124-140.

Freire, P. (1993), Pedagogy of the Oppressed, Continuum, New York, NY.

Friesen, H. (2014), "Education in a culturally diverse post-secondary classroom: a space for potential transformative learning for sustainability", The Journal of Sustainable Development, No. 7, p. 2014.

Fugate, J., Macrine, S. and Cipriano, C. (2018), "The role of embodied cognition for transforming learning", International Journal of School and Educational Psychology, Vol. 7 No. 4.

Glasser, H. and Hirsh, J. (2016), "Core competencies in learning for sustainability”, Sustainability: The Journal of Record, Vol. 9 No. 3, pp. 121-134.

Godfrey, P. (2015), “Teaching society and climate change: creating an 'earth community' in the college classroom by embodying connectedness through love", The Journal of Sustainability Education,

Griskevicius, V., Tybur, J.M. and Van den Bergh, B. (2010), “Going green to be seen: status, reputation, and conspicuous conservation”, Journal of Personality and Social Psychology, Vol. 98 No. 3, pp. 392-404.

Haraway, D. (2015), “Anthropocene, capitalocene, plantationocene, chthulucene: making kin", Environmental Humanities, Vol. 6 No. 1, pp. 159-165.

Kaijser, A. and Kronsell, A. (2014), "Climate change through the lens of intersectionality", Environmental Politics, Vol. 23 No. 3, pp. 417-433.

Kaplan, S. (1995), "The restorative benefits of nature: toward an integrative framework", Journal of Environmental Psychology, Vol. 15 No. 3, pp. 169-182.

Keltner, D. and Haidt, J. (2003), "Approaching awe, a moral, spiritual, and aesthetic emotion”, Cognition and Emotion, Vol. 17 No. 2, pp. 297-314.

Kollmuss, A. and Agyeman, J. (2002), "Mind the gap: why do people act environmentally and what are the barriers to pro-environmental behavior?", Environmental Education Research, Vol. 8 No. 3, pp. 239-260.

Laininen, E. (2019), "Transforming our worldview towards a sustainable future”, in Cook, J. (ed.). Sustainability, Human Well-Being, and the Future of Education, Palgrave Macmillan, Cham. pp 161-200.

Lakoff, G. (2008), The Political Mind, Penguin Publishing Group.

Lang, D.J., Wiek, A., Bergmann, M., Stauffacher, M., Martens, P., Moll, P., Swilling, M. and Thomas, C.J. (2012), "Transdisciplinary research in sustainability science: practice, principles, and challenges”, Sustainability Science, Vol. 7 No. 1, pp. 25-43. 
IJSHE

21,7

1604

Lange, E. (2004), "Transformative and restorative learning: a vital dialectic for sustainable societies", Adult Education Q, Vol. 54 No. 2.

Lange, E. (2018), “Transforming transformative education through ontologies of relationality", Journal of Transformative Education, Vol. 16 No. 4, pp. 280-301.

Lange, E. (2019), Transformative Learning for Sustainability. St. Francis Xavier University, Antigonish, Canada.

Lange, E. (2012), "Transforming transformative learning through sustainability and the new science", in The Handbook of Transformative Learning: Theory, Research and Practice, John Wiley and Sons.

Lavelle, B.D. (2017), "Compassion in context: tracing the buddhist roots of secular, compassion-based contemplative programs", in Seppala, E.M., Simon-Thomas, E., Brown, S.L., Worline, M.C., Cameron, C.D., Doty, J.R. (eds). The Oxford Handbook of Compassion Science, Oxford University Press, New York, NY, p. 17-25.

Lever-Tracy, C. (2010), "Sociology still lagging on climate change", Sociological Research Online, Vol. 15 No. 4, pp. 15.

McInnis, N. (1972), You are an Environment, Teaching/learning environmental attitudes.

Mcphie, J. and Clarke, D. (2019), "A walk in the park: considering practice for outdoor environmental education", in Feminist Posthumanisms, New Materialisms and Education, Ringrose, J., Warfield, K., Zarabadi, S. (eds). Routledge, New York, NY, pp. 148-168.

Morton, T. (2009), Ecology without Nature: Rethinking Environmental Aesthetics, Harvard University Press.

Murray, S. and Salter, S. (2014), "Communities of practice (CoP) as a model for integrating sustainability into higher education", In Handbook of Research on Pedagocigal Innovations for Sustainable Development, Information Science Reference.

Netherwood, K., Buchanan, J., Stocker, L. and Palmer, D. (2006), "Values education for relational sustainability: a case study of Lance Holt school and friends. In sharing wisdom for our future: environmental education in action", Wooltorton, S., Marinova, D. (eds). Australian Association of Environmental Education, Sydney, Australia, pp 249-259.

Noorgaard, K. (2011), Living in Denial. Climate Change, Emotions, and Everyday Life, MIT University Press.

O’Brien, K. and Leichenko, R. (2019), “Climate and society: transforming the future”.

O’Neil, J.K. (2018), "Transformative sustainability learning within a material-discursive ontology", Journal of Transformative Education, Vol. 16 No. 4, pp. 365-387. pp

Orr, D. (1991), What is Education for? Six Myths about the Foundations of Modern Education, and Six New Principles to Replace Them. The Learning Revolution (IC\#27), Context Institute. p 52.

O'Sullivan, E. and Taylor, M.M. (2004), Learning toward an Ecological Consciousness: Selected Transformative Practices, Palgrave Macmillan, New York, NY.

Patten, T. (2018), A New Republic of the Heart: An Ethos for Revolutionaries - a Guide to Inner Work for Holistic Change, North Atlantic Books.

Peterson, C. (2000), "The future of optimism”, American Psychologist, Vol. 55 No. 1, pp. 44-55.

Pihkala, P. (2018), "Eco-anxiety, tragedy, and hope: psychological and spiritual dimensions of climate change", Zygon ${ }^{\circledR}$, Vol. 53 No. 2, pp. 545-569.

Pisters, S.R., Vihinen, H. and Figueiredo, E. (2019), "Place based transformative learning: a framework to explore consciousness in sustainability initiatives", Emotion, Space and Society, Vol. 32.

Puis de la Bellacasa, M. (2017), Matters of Care: Speculative Ethics in More than Human Worlds, University of MN Press, Minneapolis, MN.

Schaef, A. (1987), When Society Becomes an Addict, Kindle Edition, HarperOne. 
Schellnhuber, H.J. (2002), “Coping with earth system complexity and irregularity”, Steffen, W., Jäger, J., Carson, D.J. (eds), Challenges of a Changing Earth, Springer, Heidelberg.

Schmuck, P. and Schultz, P.W. (2002), Sustainable Development as a Challenge for Psychology. Psychology of Sustainable Development, Springer, pp. 3-17.

Seligman, M. (1990), Learned Optimism, Knopf, New York, NY.

Sharma, M. (2017), Radical Transformational Leadership: Strategic Action for Change Agents, North Atlantic Books, Berkeley, CA.

Spretnak, C. (2017), Relational Reality: New Discoveries of Interrelatedness That Are Transforming the Modern World, Green Horizon Books, Topsham, ME.

Sterling, S., Glasser, H., Rieckmann, M. and Warwick, P. (2017), "More than scaling up': a critical and practical inquiry into operationalising sustainability competencies", in Envisioning Futures for Environmental and Sustainability Education, Corcoran, P.B., Weakland, J.P. and Wals, A.E.J. (eds)., Wageningen University Press, Wagingingen, The Netherlands, pp. 153-168.

Stoknes, E. (2015), What We Think About When We Try Not to Think About Global Warming, Chelsea Green Publishing, Kindle Edition.

Swanson, D., Barg, D., Tyler, D., Venema, H., Tomar, S., Bhadwal, S., Nair, S., Roy, D. and Drexhage, J. (2010), "Seven tools for creating adaptive policies", Technological Forecasting and Social Change, Vol. 77 No. 6, pp. 924-939.

Taylor, A. and Pacini-Ketchabaw, V. (2019), "Learning with children, ants, and worms in the anthropocene: towards a commonworld pedagogy of multispecies vulnerability", In Feminist Posthumanisms, New Materialisms and Education, Ringrose, J., Warfield, K. and Zarabadi, S. (eds), Routledge, New York, NY, pp. 125-147.

Taylor, E.W. and Cranton, P. (2013), "A theory in progress? Issues in transformative learning theory", European Journal for Research on the Education and Learning of Adults, Vol. 4 No. 1, pp. 33-47.

Tomlinson-Clarke, S.M. and Clarke, D.L. (Eds) (2016), Social Justice and Transformative Learning: Culture and Identity in the United States and South Africa, Routhledge, New York, NY.

Walsh, Z. (2020), "Breakdown or breakthrough? Degrowth and the great transition. Open democracy: transformation", available at: www.opendemocracy.net/en/transformation/breakdown-orbreakthrough-degrowth-and-great-transition/

Walsh, Z., Böhme, J. and Wamsler, C. (2020), Towards a Relational Paradigm in Sustainability Research, Practice, and Education, Ambio.

Walsh, Z. and Lavelle, B. (2019), "Responding with love to a civilization in crisis. Open democracy: transformation", available at: www.opendemocracy.net/en/transformation/responding-lovecivilization-crisis/

Wamsler, C. (2019), "Contemplative sustainable futures: the role of individual inner dimensions and transformation in sustainability research and education", in Leal Filho, W. and Consorte McCrea, A. (Eds), Sustainability and the Humanities, Springer International Publishing, Cham, pp. 359-373.

Wamsler, C. (2020), "Education for sustainability: fostering a more conscious society and transformation towards sustainability", International Journal of Sustainability in Higher Education, Vol. 21 No. 1.

Wamsler, C. and Restoy, F. (2020), "Emotional intelligence and the sustainable development goals: supporting peaceful, just and inclusive societies", in: Leal Filho, W. (Ed.), Encyclopedia of the UN Sustainable Development Goals, Springer.

Wamsler, C., Schäpke, N., Fraude, C., Stasiak, D., Bruhn, T., Lawrence, M., Schroeder, H. and Mundaca, L. (2020), "Enabling new mindsets and transformative skills for negotiating and activating climate action: lessons from UNFCCC conferences of the parties", Environmental Science and Policy, Vol. 112, pp. 227-235. 
IJSHE 21,7

Wang, L., Zhang, G., Shi, P., Lu, X. and Song, F. (2019), "Influence of awe on green consumption: the mediating effect of psychological ownership", Front Psycholgy, Vol. 10 No. 2484.

Wenger, E., McDermott, R. and Snyder, W. (2002), Cultivating Communities of Practice: A Guide to Managing Knowledge, Harvard Business School Press, Boston, MA.

Wells, N.M. and Evans, G.W. (2003), "Nearby nature: a buffer of life stress among rural children", Environment and Behavior, Vol. 35 No. 3, pp. 311-330.

Williams, L. (2013), "Deepening ecological relationality through critical onto-epistemological inquiry: where transformative learning meets sustainable science", Journal of Transformative Education, Vol. 11 No. 2, pp. 95-113.

Williams, L. (2018), "Transformative sustainability education and empowerment practice on indigenous lands", Journal of Transformative Education, Vol. 16 No. 4, pp. 344-364.

\section{About the authors}

Zack Walsh is a Senior Researcher of economics and governance at the One Project, San Francisco, California, USA. From 2016 to 2020, he was a Research Associate at the Institute for Advanced Sustainability Studies, Potsdam, Germany, where he co-led the A Mindset for the Anthropocene project. He has completed doctoral coursework in process studies at Claremont School of Theology and is a Fellow of the Courage of Care Coalition and a Partner of the Institute for Ecological Civilization. Zack Walsh is the corresponding author and can be contacted at: zachary.walsh@cst.edu

Jessica Böhme works as a Research Associate at the Institute for Advanced Sustainability Studies, Potsdam, Germany, and is a doctoral candidate at Leuphana University, Lüneburg, Germany, in cooperation with Lund University Centre for Sustainability Studies, Lund, Sweden. She co-leads the A Mindset for the Anthropocene project which is a transdisciplinary research project and emerging network of change agents integrating personal and socio-ecological transformations to sustainability. Her research interest is the intersection of inner and outer transformation. She has lead various international projects focused on sustainability in higher education and published various articles and books.

Brooke D. Lavelle is the Co-founder and President of the Courage of Care Coalition, Oakland, California, USA. Brooke holds a PhD degree in religious studies from Emory University, Atlanta, GA, USA, an MA in Indo-Tibetan Buddhism from Columbia University, New York, NY, USA and a BA in religion and psychology from Barnard College, New York, NY, USA. Her diverse experience in delivering contemplative programs in various social service contexts led her to deepen her understanding of the structural and systemic contributors or inhibitors to realizing compassion and care. Brooke's work now focuses on the intersection between contemplative practice and social justice.

Christine Wamsler is Professor in sustainability science at Lund University Centre for Sustainability Studies, Lund, Sweden, the former Co-director of the Lund University Centre for Societal Resilience, Lund, Sweden and a Honorary Research Fellow at the Global Development Institute, University of Manchester, England, UK. She is an expert in urban sustainability and transformation with a focus on climate change mitigation and adaptation, climate policy integration, risk reduction and resilience with more than 20 years of experience, both in theory and practice. Her work has shaped knowledge and international debates on personal, social/collective, institutional and policy transformations in the context of climate change. Wamsler has led many international projects and published more than 150 academic papers, book chapters and books on these issues.

For instructions on how to order reprints of this article, please visit our website:

www.emeraldgrouppublishing.com/licensing/reprints.htm

Or contact us for further details: permissions@emeraldinsight.com 